\title{
EFFECTS OF MILK CASEIN HYDROLYZATE SUPPLEMENTED WITH \\ PHYTOSTEROLS ON HYPERTENSION AND LIPID PROFILE IN HYPERCHOLESTEROLEMIC HYPERTENSIVE RATS
}

Pedro Ferreira-Santos ${ }^{1,2}$, Rosalía Carrón ${ }^{1,2}$, Isidra Recio ${ }^{3}$, M Ángeles Sevilla ${ }^{1,2}$, M José Montero $^{1,2^{*}}$

${ }^{1}$ Department of Physiology and Pharmacology, Faculty of Pharmacy, University of Salamanca, 37007 Salamanca, Spain.

${ }^{2}$ Biomedical Research Institute of Salamanca (IBSAL), Hospital Virgen de la Vega, 37007 Salamanca, Spain.

${ }^{3}$ Institute of Food Science Research (CIAL, CSIC-UAM), 28049 Madrid, Spain.

* Corresponding author: Dra. Ma José Montero

E-mail address: mimontero@usal.es

\section{Abbreviations}

ACh: acetylcholine; Al: atherogenic index; ALT: alanine transaminase; AST: aspartate transaminase; BW: body weight; CVD: cardiovascular diseases; DDC: ammonium diethyldithiocarbamate; HDLc: high density lipoprotein-cholesterol; LDLc: low density lipoprotein-cholesterol; LH: liver hypertrophy; LVH: left ventricular hypertrophy; NADPH: nicotinamide adenosine dinucleotide phosphate; $\mathrm{O}_{2}{ }^{-}$: Superoxide anion; PE: phenylephrine; RLU: relative luminescence units; SBP: systolic blood pressure; SEM: standard error of the mean; SNP: sodium nitroprusside; TBARS: tiobarbituric acid reactive substances; TC: Total cholesterol; TG: triacylglycerols; 


\section{Introduction}

Hypertension and hypercholesterolemia are two major controllable risk factors of cardiovascular diseases (CVD), and have become the leading cause of morbidity and mortality worldwide, representing a continuous challenge to public health efforts (O'Donnell \& Elosua, (2008). It has been established that high blood pressure combined with cholesterol levels over the desirable limits cause oxidative stress, impairment of endothelial function, vascular inflammatory responses and atherosclerosis (Ghiadoni, Taddei, \& Virdis, 2012; Koh, Oh, \& Quon, 2009). Besides pharmacological therapy, lifestyle and nutritional factors play a significant role in the prevention and treatment of pathologies as hypertension and hypercholesterolemia. The food industry, in association with research and public health institutions, has focused on the development of novel functional ingredients that aid in maintaining a normal blood pressure. These products could avoid the requirement to take antihypertensive drugs in borderline subjects (Hartmann \& Meisel, 2007; Hernandez-Ledesma, Contreras, \& Recio, 2011). Epidemiological studies suggest that the dietary intake of milk and dairy foods is related to a decreased risk of hypertension (Engberink et al., 2009). Besides their high mineral content (e.g., calcium, potassium and magnesium) that can lower blood pressure (van Mierlo et al., 2006), other milk components, such as proteins and their hydrolyzed products, have been also linked to the antihypertensive effect of dairy products (Svetkey et al., 1999; Toledo et al., 2009; Van Meijl \& Mensink, 2011). In the last two decades, antihypertensive effects of some peptides generated from milk proteins have been evaluated in experimental animals (Ehlers et al., 2011; Jäkälä et al., 2009a; Jauhiainen et al., 2010; Martínez-Maqueda et al., 2012; Sánchez-Rivera et al., 2016; Tavares et al., 2012). In this regard, several clinical trials have investigated the impact of lactotripeptides (isoleucine-proline-proline and valine-proline-proline) on blood pressure and vascular function, but only a few have examined the effects of other peptides from casein 
hydrolyzates (Fekete, Givens, \& Lovegrove, 2013; Pripp, 2008). Most of these peptides have demonstrated ACE-inhibitory activity, which is considered as one of the best strategies for hypertension management, nevertheless other mechanisms of action as antioxidant activity and opioid receptor agonist effect cannot be discarded (Nongonierma \& FitzGerald, 2015).

A hydrolyzate obtained by the action of pepsin on casein, containing the $\alpha_{\mathrm{s} 1}$-caseinderived peptides RYLGY and AYFYPEL, has been patented and commercialized under the name of Lowpept ${ }^{\circledR}$ due to its antihypertensive properties demonstrated in both, spontaneously hypertensive rats (SHR) (Contreras et al, 2009 and 2011; Sánchez et al., 2011) and hypertensive patients (Recio et al., 2011).

On the other hand, several food compounds such as long chain omega-fatty acids and phytosterols can exert beneficial cardiovascular effects by lowering plasma total cholesterol (TC) and low density lipoprotein-cholesterol (LDLC) (Lees et al., 1977; LopezHuertas, 2010; Marangoni \& Andrea, 2010; Neil, Meijer, \& Roe, 2001; Ras et al., 2016). The inhibition of cholesterol absorption in intestine is the main mechanism of action of phytosterols arising from chemical structure similarities between phytosterols and cholesterol (Calpe-Berdiel, Escolà-Gil, \& Blanco-Vaca, 2009). The effects of phytosterols and phytosterol esters on vascular function and blood pressure are controversial and useful effects beyond lowering cholesterol have been suggested.

Hypertension and high cholesterol levels are two risk factors present in a large part of the population susceptible of suffering coronary heart disease or stroke (Makovac, Thayer, \& Ottaviani, 2016; Okopień, Bułdak, \& Bołdys, 2016).

Although the beneficial effects of the administration of phytosterols or milk peptides in cardiovascular health have been reported in different studies, few have investigated the co-administration (Ehlers et al., 2012; Turpeinen et al., 2009). Therefore, the aim of this study was to investigate if the addition of phytosterols to a casein hydrolyzate could have 
beneficial synergistic effects on the management of hypertension and dyslipidemia. We assessed the effect of chronic treatment on blood pressure, vascular function, lipid profile and oxidative stress in hypercholesterolemic hypertensive rat.

\section{Materials and methods}

\subsection{Experimental protocol}

All the experiments were performed according to the European Union guidelines for the ethical care and use of laboratory animals and the protocol was approved by the Bioethics Committee of University of Salamanca (Register No: 006N²01400023665). Twenty-four male SHR 13-week old (Janvier Labs, Le Genest Saint Isle, France) were housed in boxes of 3-4 rats and maintained at a temperature of $23^{\circ} \mathrm{C}$ with $12 \mathrm{~h}$ light/dark cycles. Rats were fed on a solid standard diet (Global Diet 2014, Harlan Laboratories, Inc., Indianapolis, IN, USA) with ad libitum intake.

After 14 days of adaptation, baseline blood pressure measurements were performed. The systolic blood pressure (SBP) was measured in awake rats using the CODA tail-cuff blood pressure system (Kent Scientific, Torrington, CT, USA). This system utilizes volume pressure recording sensor technology to measure the rat tail blood pressure. Before the measurements, the rats were kept at $30-35^{\circ} \mathrm{C}$ for $10-15$ min to make detectable the pulsations of the tail artery. Arterial blood pressure measurements were carried out the same time of day (between 9 a.m. and 13 p.m.) in order to avoid the influence of the circadian cycle, and the values of SBP were obtained by estimating the average reading of 8-10 measurements. Thereafter, based on the SBP values and body weights, animals were randomized into four groups $(n=6)$.

Group C: control SHR fed a standard diet.

Group $\mathrm{CH}$ : hypercholesterolemic SHR, rats fed a high-cholesterol diet (standard diet supplemented with $1 \%$ cholesterol and $0.25 \%$ cholic acid). 
Group CHL: hypercholesterolemic SHR treated with milk casein hydrolyzate (300 $\mathrm{mg} / \mathrm{kg} /$ day) incorporated in the chow.

Group CHLP: hypercholesterolemic SHR treated with milk casein hydrolyzate (300 $\mathrm{mg} / \mathrm{kg} / \mathrm{day}$ ) and phytosterols (450 $\mathrm{mg} / \mathrm{kg} /$ day) incorporated in the chow.

The body weight (BW) was recorded weekly and blood pressure monitored every two weeks in all groups during the experimental period. Feed consumption was controlled every two days.

At the end of the treatment ( 8 weeks), animals were anaesthetized with sodium pentobarbital (60 mg/kg BW, i.p.) and blood samples were collected. After that, tissues (heart, liver and aorta) were immediately harvested, placed in chilled Krebs solution (composition in mM: $\mathrm{NaCl}, 118 ; \mathrm{KCl}, 4.7 ; \mathrm{CaCl}_{2}, 2.5 ; \mathrm{KH}_{2} \mathrm{PO}_{4}, 1.2 ; \mathrm{MgSO}_{4}, 1.2 ; \mathrm{NaHCO}_{3}$, 25 and glucose, 11, $\mathrm{pH}=7.4$ ) and appropriately processed for further studies. Blood samples were centrifuged at $350 \mathrm{~g}$ for $10 \mathrm{~min}$, at $4{ }^{\circ} \mathrm{C}$, to obtain the plasma that was kept at $-80^{\circ} \mathrm{C}$ until use.

\subsection{Left ventricular hypertrophy}

The atrium was removed from the heart and all the epicardial fat was scraped off. The right and the left ventricles were separated, regarding the interventricular septum as an integral part of the left ventricle, and this portion was weighed. The left ventricular hypertrophy $(\mathrm{LVH})$ index was calculated using left ventricle weight/BW ratio.

\subsection{Morpho-histology of liver}

Isolated liver was washed with chilly Krebs solution and moisture was eliminated with filter paper. The liver hypertrophy (LH) index was determined using liver weight/BW ratio. A portion of large lobe of the liver was fixed in $10 \%$ formaldehyde for 72 hours. Fixed specimens were processed for paraffin embedding and $5 \mu \mathrm{m}$ slices were stained with 
hematoxylin-eosin. Histological sections were examined under an optical microscope and images were captured using a high-resolution digital camera (Olympus DP50, Tokyo, Japan). Size of hepatocytes was measured as an average of 10 hepatocytes taken from different zones of histological sections using ImageJ software (US National Institutes of Health, http://rsb.info.nih.gov/ii//). The hepatic steatosis was measured as percent area fraction of fat vacuole surrounding periportal area/total area of image. Adobe Photoshop (Adobe Photoshop ${ }^{\circledR}$ CS3, Microsoft) program was used to image analysis.

\subsection{Biochemical parameters measurement}

Triacylglycerols (TG), TC, high density lipoprotein-cholesterol (HDLc), alanine transaminase (ALT), aspartate transaminase (AST) levels were analyzed in plasma using reagent strips for quantitative measurement (Spotchem ${ }^{\mathrm{TM}} \mathrm{II}$, Arkray, Shiga, Japan) in a fully automatic biochemical analyzer (Spotchem ${ }^{\mathrm{TM}}$ EZ sp-4430, Arkray, Shiga, Japan). LDLc was calculated according to the formula: LDLc $=$ TC-(HDLC+TG/5) and the atherogenic index (Al) was calculated as follows: $\mathrm{Al}=(\mathrm{TC}-\mathrm{HDLC}) / \mathrm{HDLC}(\mathrm{Olmez}$ et al., 2015).

\subsection{Lipid peroxidation (TBARS)}

Lipid peroxidation, a marker of oxidative stress, was estimated in plasma by measurement of thiobarbituric acid-reactive substances (TBARS) previously described by Ohkawa, Ohishi and Yagi (1979) with minor modifications (Kassan et al., 2009). The results were expressed as concentration of TBARS $(\mu \mathrm{M})$.

\subsection{Vascular reactivity measurements}

The thoracic aorta was carefully cleaned of fat and connective tissue and cut into rings (3 $\mathrm{mm}$ length) that were placed between stainless steel hooks and set up in organ chambers 
filled with $5 \mathrm{~mL}$ of Krebs solution, bubbled with carbogen $\left(5 \% \mathrm{CO}_{2}, 95 \% \mathrm{O}_{2}\right)$ and kept at 37 ${ }^{\circ} \mathrm{C}$. One of the hooks was fixed to the bath and the other connected to an isometric force transducer (UF1, Harvard apparatus Inc., Holliston, MA, USA). Force was recorded on a PC computer using Lab Chart version 3.4 software and a Power Lab/800 data acquisition system (AD Instruments, Oxford, UK). All rings were allowed to equilibrate for $1 \mathrm{~h}$ at a resting tension of $2 \mathrm{~g}$. The Krebs solution was periodically changed and tension was reset during this period. Then, the vessels were exposed to phenylephrine $\left(P E, 10^{-6} \mathrm{M}\right)$ and the presence of functional endothelium was assessed by the ability of acetylcholine (ACh, $10^{-6}$ M) to induce relaxation. After a washout period, cumulative concentration-response curves to $\mathrm{PE}\left(10^{-8}\right.$ to $\left.10^{-4} \mathrm{M}\right)$ were obtained. After pre-contraction with $\mathrm{PE}\left(10^{-6} \mathrm{M}\right)$ and steady maximal contraction, cumulative concentration-response curves were obtained for ACh $\left(10^{-8}\right.$ to $\left.10^{-4} \mathrm{M}\right)$ or sodium nitroprusside (SNP, $10^{-9}$ to $\left.10^{-4} \mathrm{M}\right)$. Each curve was obtained in different rings.

Responses to PE were expressed as mg of contraction and responses to ACh and SNP as percentage of PE contraction.

\subsection{Detection of vascular superoxide anion}

Superoxide anion $\left(\mathrm{O}_{2}{ }^{-}\right)$production was assessed by lucigenin-enhanced chemiluminescence assay. Briefly, segments of thoracic aorta were incubated in ROS phosphate buffer (composition in $\mathrm{mM}: \mathrm{KH}_{2} \mathrm{PO}_{4}, 50$; EGTA, 1 and sucrose, 150, $\mathrm{pH}=7.4$ ) supplemented with ammonium diethyldithiocarbamate (DDC, $10 \mathrm{mM}$ ), gassed with carbogen and maintained at $37^{\circ} \mathrm{C}$ for $15 \mathrm{~min}$. Then, samples were transferred into tubes containing ROS phosphate buffer, DDC (10 mM), nicotinamide adenosine dinucleotide phosphate (NADPH, 10 $\left.10^{-4} \mathrm{M}\right)$ and lucigenin $(5 \mu \mathrm{M})$. Lucigenin chemiluminescence was recorded every $10 \mathrm{~s}$ for $5 \mathrm{~min}$ in a luminometer (LUMAT LB-9507, Berthold Technologies, 
Bad Wildbad, Germany). Production of $\mathrm{O}_{2}{ }^{-}$is expressed as relative luminescence units $(\mathrm{RLU}) / \mathrm{min} / \mathrm{mg}$ dry tissue.

\subsection{Compounds}

The milk casein hydrolyzate $\left(\right.$ Lowpept $^{\circledR}$ ) was prepared using commercial casein (Promilk 85, Arras Cedex, France) that was hydrolyzed with food grade pepsin (Biocatalysts, Cardiff, UK), according to our previous paper (Contreras et al., 2011) and provided by Innaves S.A. (Vigo, Spain).

Phytosterols were a concentrate of sterols containing mainly sterols from vegetable oils (Vitasterol $^{\circledR}$ S-80 WDP (90\%), provided by Vitae Caps S.A., Toledo, Spain). Cholesterol (PubChem CID: 5997); cholic acid (PubChem CID: 221493); acetylcholine chloride (PubChem CID: 6060); phenylephrine hydrochloride (PubChem CID: 5284443); sodium nitroprusside (PubChem CID: 11953895); thiobarbituric acid (PubChem CID: 2723628), tricloroacetic acid (PubChem CID: 6421), ammonium diethyldithiocarbamate (PubChem CID: 88794), nicotinamide adenosine dinucleotide phosphate (PubChem CID: 5884) and lucigenin (PubChem CID:65099) were purchased from Sigma-Aldrich (Madrid, Spain). All other chemicals were of analytical grade. Stock solutions of the drugs were prepared in ultrapure water, stored at $-20^{\circ} \mathrm{C}$ and appropriate dilutions were made on the day of the experiments.

\subsection{Statistical analysis}

Data are expressed as means \pm standard error of the mean (SEM). The cumulative concentration-response curves by ACh, SNP and PE were fitted to a logistic equation and the negative logarithm of the concentration producing half maximal effect $\left(\mathrm{pD}_{2}\right)$ were calculated. Concentration-response curves comparison was performed according to the extra sum of squares F-test principle. The level of statistical significance was determined 
by one-way analysis of variance (ANOVA) followed by Bonferroni's test for multiple comparisons and two-way ANOVA for blood pressure data. Significance was accepted at $\mathrm{P}<0.05$. Fitting and statistical analysis were performed using GraphPad Prism ${ }^{\circledR}$ software (version 5.0; GraphPad Software, Inc., San Diego, CA, USA).

\section{Results}

\subsection{Blood pressure}

Blood pressure values during the 8 weeks treatment are presented in Fig. 1. The induction of hypercholesterolemic status did not alter the SBP. The long-term treatment with milk casein hydrolyzate with or without phytosterols decreased the SBP of the hypertensive hypercholesterolemic rats from 4 weeks of treatment. During the treatment, there were no significant differences in SBP values between CHL and CHLP groups.

\subsection{Left ventricular hypertrophy}

There were no differences in the daily dietary intake or in the BW among groups (Table 1). Hypercholesterolemic diet did not modify the LVH index compared with control group, but both treatments resulting in a significant reduction of this parameter (Fig. 2).

\subsection{Morpho-histology of liver}

In contrast to the normal healthy appearance of the liver in the $\mathrm{C}$ group, the highcholesterol diet for 8 weeks induced an increase of liver size (Fig. 3). Liver from rats fed only with hypercholesterolemic diet exhibited increase in size hepatocytes $(\mathrm{CH}=896 \pm 65$ versus $\left.C=430 \pm 17 \mu \mathrm{m}^{2}, \mathrm{p}<0.05\right)$, massive fatty changes and severe steatosis, as it is shown in histological sections (Fig. 4). Treatment with milk casein hydrolyzate failed to

reduce hypertrophy $\left(\mathrm{CHL}=855 \pm 27 \mu \mathrm{m}^{2}\right)$ and steatosis, however phytosterols addition 
reversed the hepatocytes to normal values $\left(\mathrm{CHLP}=569 \pm 74 \mu \mathrm{m}^{2}\right)$ and the hepatic steatosis was remarkably lower, and the hepatic cells exhibited normal histology.

\subsection{Biochemical parameters and lipid peroxidation assessment}

Table 1 summarizes the parameters measured in plasma in order to evaluate the changes on lipid profile, transaminases and the extent of lipid peroxidation between the different groups. The hypercholesterolemic diet (group $\mathrm{CH}$ ) dramatically increased the plasmatic levels of TC, LDLC and Al, a slight decrease of HDLc was also measured and no significant changes were observed in TG levels, which demonstrated the hyperlipidemic model was successfully established. Even though the oral administration of milk casein hydrolyzate during 8 weeks did not cause any effect in preventing alterations related to the hypercholesterolemic status, the addition of phytosterols resulted in a significantly recovery of TC, LDLC levels and AI.

The levels of enzymes AST and ALT were greater in $\mathrm{CH}$ group compared with the C group, indicating that lipid accumulation was harmful to the liver. Treatment with milk casein hydrolyzate produced a significant reduction in ALT, and a slight attenuation in AST not statistically significant compared to the hypercholesterolemic SHR group untreated. The addition of phytosterols to casein hydrolyzate produced a greater effect at the level of these hepatic enzymes, obtaining similar values to the control SHR group.

Moreover, rats receiving the hypercholesterolemic diet showed a remarkable increase of lipid peroxidation products in plasma. Although the treatment with milk casein hydrolyzate slightly attenuated lipid peroxidation levels, only the incorporation of phytosterols to the diet was able to get a significant effect respect to $\mathrm{CH}$ group.

\subsection{Vascular reactivity}


Endothelium-dependent relaxation induced by ACh showed no difference between C $\left(E \max =42.2 \pm 2.1 \%\right.$ and $\left.\mathrm{pD}_{2}=7.5 \pm 0.2\right)$ and $\mathrm{CH}$ groups $(\mathrm{Emax}=45.8 \pm 2.0 \%$ and $\mathrm{pD}_{2}=7.5 \pm 0.1$ ), but the groups treated with milk casein hydrolyzate regardless of the presence $\left(E \max =57.4 \pm 4.1 \%\right.$ and $\left.\mathrm{pD}_{2}=7.7 \pm 0.3\right)$ or absence $(E \max =57.0 \pm 3.7 \%$ and $\mathrm{pD}_{2}=7.5 \pm 0.2$ ) of phytosterols showed significantly greater relaxation to ACh (Fig. $5 \mathrm{a}$ ). SNP-induced endothelium-independent relaxation reached proximately $100 \%$ in all groups. The sensibility to this agent was higher in vessels of treated animals with milk casein hydrolyzate $\left(\mathrm{pD}_{2}=7.8 \pm 0.1\right)$ or milk casein hydrolyzate plus phytosterols $\left(\mathrm{pD}_{2}=7.9 \pm 0.1\right)$ than in $\mathrm{CH}$ group and not differences between $\mathrm{C}$ and $\mathrm{CH}$ groups were observed $\left(\mathrm{pD}_{2}=7.4 \pm 0.1\right.$ and $\mathrm{pD}_{2}=7.6 \pm 0.1$, respectively) (Fig. 5b).

Phenylephrine-induced contractile responses in aortic rings from different groups are shown in Fig. 6. Rings from rats fed with hypercholesterolemic diet did not modify the response to phenylephrine ( $\mathrm{C}$ group, Emax $=2104 \pm 105 \mathrm{mg}$ and $\mathrm{CH}$ group, Emax $=2343 \pm 206 \mathrm{mg}$ ), and treatment with milk casein hydrolyzate achieved a significantly reduction of contractile response $(E \max =1495 \pm 142 \mathrm{mg})$. Additional treatment with phytosterols did not modify this response (Emax=1707 $\pm 219 \mathrm{mg})$.

\subsection{Vascular superoxide anion}

The $\mathrm{O}_{2}^{\cdot-}$ production stimulated by NADPH in aortic rings is shown in Fig. 7. Hypercholesterolemic diet caused an increase of this free radical. The treated groups with casein hydrolyzate shown statistical significant reduction in generation of $\mathrm{O}_{2}{ }^{\cdot-}$. Interesting, these levels were lower in group receiving casein hydrolyzate with phytosterols.

\section{Discussion}

This investigation has been conducted in SHR with experimentally induced hypercholesterolemia. SHR is a phenotype-driven rat experimental model in which 
hypertension is associated with cardiac hypertrophy, endothelial dysfunction and oxidative stress; and extensively used in research since resembles human hypertension (Lerman et al., 2005). The diet-induced hypercholesterolemia is used to promote alterations on lipid profile, redox balance and liver damage (Abreu et al., 2014; Deepa \& Varalakshmi, 2003). Hypertension and hypercholesterolemia are two major risk factors of cardiovascular diseases and great efforts are being made to control them.

The long-term effects of a milk casein hydrolyzate containing active peptides or fortified with phytosterols were investigated on blood pressure, morphological and histological alterations of organs, vascular function, lipid profile and oxidative stress. Phytosterols were included in the study to find out a possible additional effect on the aforementioned variables.

Our previous studies showed that long-term treatment with milk casein hydrolyzate containing the $\alpha_{\mathrm{s} 1}$-casein derived peptides, RYLGY and AYFYPEL, attenuated the development of hypertension, exerted a cardiovascular protective effect in SHR (Sánchez et al., 2011) and decreased blood pressure (about $12 \mathrm{mmHg}$ ) in hypertensive subjects (Recio et al., 2011). Recently, bioactive milk peptides have gained interest because of their notable antihypertensive, antioxidant, anti-inflammatory, and hypocholesterolemic effects (Hsieh et al., 2015). In the current study, the casein hydrolyzate decreased SBP in hypercholesterolemic SHR, but any additional reduction on blood pressure was observed after supplementation with phytosterols. Therefore, we assume that phytosterols do not contribute to the antihypertensive effect. In this sense, Kim et al. (2008) also reported no effects on blood pressure in conscious SHR fed with a diet fortified with phytosterol esters for 9 weeks and other studies in human pointed at the ineffectiveness of phytosterols or stanols to reduce blood pressure (Hallikainen et al., 2006; Tapola et al., 2004). Hypertension is a major cause of cardiac hypertrophy, which frequently leads to heart failure (Gradman \& Alfayoumi, 2006). In concordance with our results on blood pressure 
above mentioned, additional alterations in LVH caused by hypercholesterolemic diet were not observed, however treatment with milk casein hydrolyzate regardless of the presence of phytosterols decreased the hypertrophic index.

It is known that SHR from 10 to 12 week-old, show marked endothelial dysfunction (Bernatova et al., 2009). As expected, our results on vascular reactivity in aortic rings showed impaired endothelial function in control SHR fed a standard diet while the induction of a hypercholesterolemic status did not aggravate vascular dysfunction. Lorkowska et al. (2006) reported similar results, justified by a modest lipid accumulation in the vascular wall insufficient to induce alterations in vascular function.

We had previously reported that relaxation to ACh on aortic and mesenteric rings from SHR improved after 6-week treatment with the casein hydrolyzate and contraction to phenylephrine was lower (Sánchez et al. 2011). Here, using aorta from hypercholesterolemic SHR we corroborated the benefits of casein hydrolyzate on endothelial function and evidenced the ineffectiveness of supplementation with phytosterols.

In agreement with our results, other researchers also observed no additional effects on vasorelaxation response in arteries from SHR treated with fermented milk products containing tripeptides when plant sterols were co-administered (Ehlers et al., 2011 and 2012; Jäkälä et al., 2009b).It has to be noted that, both, milk casein hydrolyzate alone or combined with phytosterols increased the sensitivity of the aortic rings to the endotheliumindependent vasodilator SNP. However, previous reports had not shown differences on response to SNP between control animals and treated with milk casein derived products (Jäkälä et al., 2009a and 2009b; Sánchez et al., 2011). It can be hypothesized that this discrepancy could be due to the use of older rats in the present study, in which arterial dysfunction might have further progressed, and thus, the positive effect of milk casein 
hydrolysate on smooth muscle cells could be more pronounced; in addition to a longer treatment period in comparison with previous studies.

The effect of diets supplemented with phytosterols on vascular function have not received much attention, and it is difficult to precise its effect, because they are often incorporated into products together with other bioactive components. In this regard, Hallikainen et al. (2006) administered either plant sterols or stanols esters to hypercholesterolemic subjects for 10 weeks, and this treatment did not affect the dilatation of the brachial artery. In another study, plant sterols consumption for 2 years did not significantly improve carotid artery compliance in healthy subjects (Raitakari, Salo, \& Ahotupa, 2008). A study with male C57/BI6 mice fed with 2\% plant sterol ester-supplemented diet for 4 weeks showed that the endothelium-dependent relaxation of aortic rings was slightly impaired in comparison to the controls (Weingartner et al., 2008).

Elevated plasmatic levels of TC and LDLc along with low HDLC are often associated with premature atherosclerosis and CVD (Assmann \& Gotto, 2004). High cholesterol diet raises plasma LDLc levels and oxidative stress, both result in the production of oxidized LDLc and thereby increases atherosclerotic plaque formation. The cardioprotective effects of HDLc are associated to its role in reversing cholesterol transport, its effects on endothelial cells, and its antioxidant activity (Akalin-Çiftçi et al., 2015).As expected, our results in hypercholesterolemic untreated rats reproduced this pattern with lower HDLc and higher TC and LDLc levels than those from animals receiving standard diet, which led to an increased Al. Morphological and biochemical studies also revealed liver injury characterized by hepatomegaly and high levels of AST and ALT enzymes. Moreover, histology revealed large size hepatocytes and steatosis in $\mathrm{CH}$ group. Similar results have been reported by others researchers in Goto-Kakizaki and Wistar rats (Kengkoom et al.,2013) and Fischer rats (Abreu et al., 2014) after hypercholesterolemic diets. Treatment with casein hydrolyzate alone failed to revert most of the alterations previously indicated, 
thus it seems that phytosterols were solely responsible for improving the lipidic profile and hepatic damage.

Both hypertension and hypercholesterolemia are associated with a large increase in reactive oxygen species, a situation which finally ends with oxidative stress that promotes cell growth, inflammation, extracellular matrix deposition, etc; resulting in endothelial dysfunction, cardiac hypertrophy, lipid peroxidation, etc. (Ellulu et al., 2016; Montezano \& Touyz, 2014). To demonstrate any implication of the treatments on oxidative stress we measured the TBARS and $\mathrm{O}_{2^{-}}{ }^{-}$. In this sense, it is well known that these biomarkers are higher in SHR than in normotensive rats. We found that both were significantly increased when SHR were fed with the hypercholesterolemic diet. Unlike results previously discussed, the co-administration of phytosterols was effective, since the reduction of lipid peroxidation in the groups of animals treated with milk casein hydrolysate, respect to $\mathrm{CH}$ group, achieved statistical significance with the addition of phytosterols. The determination of $\mathrm{O}_{2} \bullet^{-}$supported the antioxidant action of the hydrolyzate and the synergistic effect of phytosterols. It is worth noting that, in addition to the antihypertensive effect, in vitro scavenger activity has been already reported for peptides from this casein hydrolyzate (Contreras et al., 2009) and otherwise, phytosterols have displayed an important hypolipidemic activity (Neil, Meijer, \& Roe, 2001; Marangoni \& Andrea, 2010). Therefore, the joint administration of both compounds would be suitable when hypertension and hypercholesterolemia coexist.

\section{Conclusion}

In hypercholesterolemic hypertensive rats, chronic treatment with milk casein hydrolyzate improved the parameters related to the hypertensive process, while the incorporation of phytosterols prevented the alterations caused by the hipercholesterolemia. Just the increase in oxidative stress, present in hypertension and hipercholesterolemia, showed a 
greater reduction after co-administration. Therefore, the administration of the casein hydrolyzate fortified with phytosterols would be indicated when both disorders occur together.

\section{Conflict of interest}

The authors declare no conflicts of interest.

\section{Acknowledgements}

This work was supported by project FP7-SME-2012-315349 (FOFIND) financed by the European Commission. Pedro Ferreira Santos was the recipient of a fellowship funded from this project.

The authors like to thank to Belén Díaz and Beatriz Gómez, from INNAVES SA, for the preparation and supply of the milk casein hydrolyzate and phytosterols.

\section{References}

Abreu, I. C. M. E. D., Guerra, J. F. D. C., Pereira, R. R., Silva, M., Lima, W. G. D., Silva, M. E., \& Pedrosa, M. L. (2014). Hypercholesterolemic diet induces hepatic steatosis and alterations in mRNA expression of NADPH oxidase in rat livers. Arquivos Brasileiros de Endocrinologia \& Metabologia, 58(3), 251-259.

Assmann, G., \& Gotto, A.M.Jr. (2004). HDL Cholesterol and protective factors in atherosclerosis. Circulation, 109(23 suppl 1), III8-14.

Akalin-Çiftçi, G., Ertorun, İ., Akalin, A., Alataş, I.Ö., \& Musmul, A. (2015). The effects of atorvastatin on antioxidant/antiinflammatory properties of HDLs in hypercholesterolemics. Turkish Journal of Medical Sciences, 45(2), 345-351. 
Bernatova, I., Conde, M.V., Kopincova. J., González, M.C., Puzserova, A., \& Arribas, S.M. (2009). Endothelial dysfunction in spontaneously hypertensive rats: focus on methodological aspects. Journal of Hypertension, 27(6), S27-31.

Calpe-Berdiel, L., Escolà-Gil, J.C., \& Blanco-Vaca, F. (2009). New insights into the molecular actions of plant sterols and stanols in cholesterol metabolism. Atherosclerosis, 203(1), 18-31.

Contreras, M.M., Carrón, R., Montero, M.J., Ramos, M., \& Recio, I. (2009). Novel caseinderived peptides with antihypertensive activity. International Dairy Journal, 19(10), 566573.

Contreras, M.M., Carrón, R., Montero, M.J., Ramos, M., \& Recio, I. (2011). Food-grade production of an antihypertensive casein hydrolysate and resistance of active peptides to drying and storage. International Dairy Journal, 21(7), 470-476.

Deepa, P.R., \& Varalakshmi, P. (2003). Salubrious effect of low molecular weight heparin on atherogenic diet-induced cardiac, hepatic and renal lipid peroxidation and collapse of antioxidant defences. Molecular and Cellular Biochemistry, 254(1-2), 111-116.

Ehlers, P.I., Kivimäki, A.S., Siltari. A., Turpeinen, A.M., Korpela, R., \& Vapaatalo, H. (2012). Plant sterols and casein-derived tripeptides attenuate blood pressure increase in spontaneously hypertensive rats. Nutrition Research, 32(4), 292-300.

Ehlers, P.I., Kivimäki, A.S., Turpeinen, A.M., Korpela, R., \& Vapaatalo, H. (2011). High blood pressure-lowering and vasoprotective effects of milk products in experimental hypertension. British Journal of Nutrition, 106(9), 1353-1363.

Ellulu, M.S., Patimah, I., Khaza'ai, H., Rahmat, A., Abed, Y., \& Ali, F. (2016). Atherosclerotic cardiovascular disease: a review of initiators and protective factors. Inflammopharmacology, 24(1), 1-10.

Engberink, M.F., Hendriksen, M.A., Schouten, E.G., van Rooij, F.J., Hofman, A., Witteman, J.C., \& Geleijnse, J.M. (2009). Inverse association between dairy intake and 
hypertension: the rotterdam study. American Journal of Clinical Nutrition, 89(6), 18771883.

Fekete, A. A., Givens, D. I., \& Lovegrove, J. A. (2013). The impact of milk proteins and peptides on blood pressure and vascular function: a review of evidence from human intervention studies. Nutrition research reviews, 26(02), 177-190.

Ghiadoni, L., Taddei, S., \& Virdis, A. (2012). Hypertension and endothelial dysfunction: therapeutic approach. Current Vascular Pharmacology, 10(1), 42-60.

Gradman, A.H., \& Alfayoumi, F. (2006). From left ventricular hypertrophy to congestive heart failure: management of hypertensive heart disease. Progress in Cardiovascular Diseases, 48(5), 326-341.

Hallikainen, M., Lyyra-Laitinen, T., Laitinen, T., Agren, J.J., Pihlajamäki, J., Rauramaa, R., Miettinen, T.A., \& Gylling, H. (2006). Endothelial function in hypercholesterolemic subjects: effects of plant stanol and sterol esters. Atherosclerosis, 188(2), 425-432.

Hartmann, R., \& Meisel, H. (2007). Food-derived peptides with biological activity: from research to food applications. Current Opinion in Biotechnology, 18(2), 163-169.

Hernandez-Ledesma, B., Contreras, M.M., \& Recio, I. (2011). Antihypertensive peptides: production, bioavailability and incorporation into foods. Advances in Colloid and Interface Science, 165(1), 23-35.

Hsieh, C.C., Hernández-Ledesma, B., Fernández-Tomé, S., Weinborn, V., Barile, D., \& de Moura Bell, J.M. (2015). Milk proteins, peptides, and oligosaccharides: effects against the 21st century disorders. BioMed Research International, 2015, 146840.

Jäkälä, P., Hakala, A., Turpeinen, A.M., Korpela, R., \& Vapaatalo, H. (2009a). Caseinderived bioactive tripeptides Ile-Pro-Pro and Val-Pro-Pro attenuate the development of hypertension and improve endothelial function in salt-loaded Goto-Kakizaki rats. Journal of Functional Foods, 1(4), 266-274. 
Jäkälä, P., Pere, E., Lehtinen, R., Turpeinen, A., Korpela, R., \& Vapaatalo, H. (2009b). Cardiovascular activity of milk casein-derived tripeptides and plant sterols in spontaneously hypertensive rats. Journal of Physiology and Pharmacology, 60(4), 11-20.

Jauhiainen, T., Pilvi, T., Cheng, Z.J., Kautiainen, H., Müller, D.N., Vapaatalo, H., Korpela, R., \& Mervaala, E. (2010). Milk products containing bioactive tripeptides have an antihypertensive effect in double transgenic rats (dTGR) harbouring human renin and human angiotensinogen genes. Journal of Nutrition and Metabolism, 2010, 287030.

Kassan, M., Montero, M.J., \& Sevilla, M.A. (2009). Chronic treatment with pravastatin prevents early cardiovascular changes in spontaneously hypertensive rats. British Journal of Pharmacology, 158(2), 541-547.

Kengkoom, K., Klinkhamhom, A., Sirimontaporn, A., Singha, O., Ketjareon, T., Panavechkijkul, Y., Seriwatanachai, D., Ukong, S., \& Ampawong, S. (2013). Effects on high cholesterol-fed to liver, retina, hippocampus, and Harderian gland in Goto-Kakizaki rat. International Journal of Clinical and Experimental Pathology, 6(4), 639-649.

Kim, B.H., Sandock, K.D., Robertson, T.P., Lewis, S.J., \& Akoh, C.C. (2008). Dietary structured lipids and phytosteryl esters: blood lipids and cardiovascular status in spontaneously hypertensive rats. Lipids, 43(1), 55-64.

Koh, K.K., Oh, P.C., \& Quon, M.J. (2009). Does reversal of oxidative stress and inflammation provide vascular protection? Cardiovascular Research, 81(4), 649-659.

Lees, A.M., Mok, H.Y., Lees, R.S., McCluskey, M.A., \& Grundy, S.M. (1977). Plant sterols as cholesterol-lowering agents: clinical trials in patients with hypercholesterolemia and studies of sterol balance. Atherosclerosis, 28(3), 325-338.

Lerman, L. O., Chade, A. R., Sica, V., \& Napoli, C. (2005). Animal models of hypertension: an overview. Journal of Laboratory and Clinical Medicine, 146(3), 160-173.

Lopez-Huertas, E. (2010). Health effects of oleic acid and long chain omega-3 fatty acids (EPA and DHA) enriched milks. A review of intervention studies. Pharmacological Research, 61(3), 200-207. 
Lorkowska, B., Bartus, M., Franczyk, M., Kostogrys, R.B., Jawien, J., Pisulewski, P.M., \& Chlopicki, S. (2006). Hypercholesterolemia does not alter endothelial function in spontaneously hypertensive rats. Journal of Pharmacology and Experimental Therapeutics, 317(3), 1019-1026.

Makovac, E., Thayer, J.F., \& Ottaviani, C. (2016). A meta-analysis of non-invasive brain stimulation and autonomic functioning: Implications for brain-heartpathways to cardiovascular disease. Neuroscience \& Biobehavioral Reviews, Pii, S01497634(16)30036-7.

Marangoni, F., \& Andrea, P. (2010). Phytosterols and cardiovascular health. Pharmacological Research, 61(3), 193-199.

Martínez-Maqueda, D., Miralles, B., Recio, I., \& Hernández-Ledesma, B. (2012). Antihypertensive peptides from food proteins: A review. Food \& Function, 3(4), 350-361.

Montezano, A.C., \& Touyz, R.M. (2014). Reactive oxygen species, vascular Noxs, and hypertension: focus on translational and clinical research. Antioxidants \& redox signaling, 20(1), 164-182.

Neil, H.A., Meijer, G.W., \& Roe, L.S. (2001). Randomised controlled trial of use by hypercholesterolaemic patients of a vegetable oil sterol enriched fat spread.

Atherosclerosis, 156(2), 329-337.

Nongonierma, A. B., \& FitzGerald, R. J. (2015). The scientific evidence for the role of milk protein-derived bioactive peptides in humans: A Review. Journal of Functional Foods, 17, 640-656.

O'Donnell, C. J., \& Elosua, R. (2008). Cardiovascular risk factors. Insights from Framingham heart study. Revista Espanola de Cardiologia (English Edition), 61(3), 299310.

Ohkawa, H., Ohishi, N., \& Yagi, K. (1979). Assay for lipid peroxides in animal tissues by thiobarbituric acid reaction. Analytical Biochemistry, 95(2), 351-358. 
Okopień, B., Bułdak, Ł., \& Bołdys, A. (2016). Current and future trends in the lipid lowering therapy. Pharmacological Reports, 68(4), 737-747.

Olmez, E., Vural, K., Gok, S., Ozturk, Z., Kayalar, H., Ayhan, S., \& Var, A. (2015). Olive leaf extract improves the atherogenic lipid profile in rats fed a high cholesterol diet. Phytotherapy Research, 29(10), 1652-1657.

Pripp, A.H. (2008). Effect of peptides derived from food proteins on blood pressure: a meta-analysis of randomized controlled trials. Food \& Nutrition Research, 52, DOI: 10.3402/fnr.v52i0.1641.

Raitakari, O.T., Salo, P., \& Ahotupa, M. (2008). Carotid artery compliance in users of plant stanol ester margarine. European Journal of Clinical Nutrition, 62(2), 218-224.

Ras, R.T., Koppenol, W.P., Garczarek, U., Otten-Hofman, A., Fuchs, D., Wagner, F., \& Trautwein, E.A. (2016). Increases in plasma plant sterols stabilize within four weeks of plant sterol intake and are independent of cholesterol metabolism. Nutrition, Metabolism and Cardiovascular Diseases, 26(4), 302-309.

Recio, I, Contreras, M.M., Gómez-Sala, B., Vázquez, C., Fernández-Escribano, H., \& del Campo, R. (2011). Effect of a casein hydrolysate containing novel peptides in hypertensive subjects. Annals of Nutrition and Metabolism, 58(3), 16-17.

Sánchez, D., Kassan, M., Contreras, M.M., Carrón, R., Recio, I., Montero, M.J., \& Sevilla, M.A. (2011). Long-term intake of a milk casein hydrolysate attenuates the development of hypertension and involves cardiovascular benefits. Pharmacological Research, 63(5), 398-404.

Sánchez-Rivera, L., Santos, P.F., Miralles, B., Carrón, R., Montero, M.J., \& Recio, I. (2016). Peptide fragments from $\beta$-casein $f(134-138)$, HLPLP, generated by the action of rat blood plasma peptidases show potent antihypertensive activity. Food Research International, 88, 348-353 
Svetkey, L.P., Simons-Morton, D., Vollmer, W.M., Appel, L.J., Conlin, P.R., Ryan, D.H., Ard, J., \& Kennedy, B.M. (1999). Effects of dietary patterns on blood pressure: subgroup analysis of the Dietary Approaches to Stop Hypertension (DASH) randomized clinical trial. Archives of Internal Medicine, 159(3), 285-293.

Tapola, N.S., Lyyra, N.S., Lyyra, M.L., Karvonen, H.M., Uusitupa, M.I., \& Sarkkinen, E.S. (2004). The effect of meat products enriched with plant sterols and minerals on serum lipids and blood pressure. International Journal of Food Sciences and Nutrition, 55(5), 389-397.

Tavares, T., Sevilla, M.Á., Montero, M.J., Carrón, R., \& Malcata, F.X. (2012). Acute effect of whey peptides upon blood pressure of hypertensive rats, and relationship with their angiotensin-converting enzyme inhibitory activity. Molecular nutrition \& food research, 56(2), 316-324.

Toledo, E., Delgado-Rodríguez, M., Estruch, R., Salas-Salvadó, J., Corella, D., GomezGracia, E., Fiol, M., Lamuela-Raventós, R.M., Schröder, H., Arós, F., Ros, E., RuízGutiérrez, V., Lapetra, J., Conde-Herrera, M., Sáez, G., Vinyoles, E., \& MartínezGonzález, M.A. (2009). Low-fat dairy products and blood pressure: follow-up of 2290 older persons at high cardiovascular risk participating the PREDIMED study. British Journal of Nutrition, 101(1), 59-67.

Turpeinen, A. M., Kumpu, M., Rönnback, M., Seppo, L., Kautiainen, H., Jauhiainen, T., Vapaatalo, H. \& Korpela, R. (2009). Antihypertensive and cholesterol-lowering effects of a spread containing bioactive peptides IPP and VPP and plant sterols. Journal of Functional Foods, 1(3), 260-265

van Mierlo, L.A., Arends, L.R., Streppel, M.T., Zeegers, M.P., Kok, F.J., Grobbee, D.E., \& Geleijnse, J.M. (2006). Blood pressure response to calcium supplementation: a metaanalysis of randomized controlled trials. Journal of Human Hypertension, 20(8), 571-580.

Van Meijl, L.E., \& Mensink, R.P. (2011). Low-fat dairy consumption reduces systolic blood pressure, but does not improve other metabolic risk parameters in overweight and obese subjects. Nutrition, Metabolism and Cardiovascular Diseases, 21(5), 355-361. 
Weingärtner, O., Lütjohann, D., Ji, S., Weisshoff, N., List, F., Sudhop, T., von Bergmann, K., Gertz, K., König, J., Schäfers, H.J., Endres, M., Böhm, M., \& Laufs, U. (2008). Vascular effects of diet supplementation with plant sterols. Journal of the American College of Cardiology, 51(16), 1553-1561. 


\section{FIGURES CAPTIONS}

Figure 1. Systolic blood pressure (SBP) in control SHR (C), untreated hypercholesterolemic SHR $(\mathrm{CH})$, treated hypercholesterolemic SHR with milk casein hydrolyzate $(\mathrm{CHL})$ or milk casein hydrolyzate plus phytosterols (CHLP).

Values are expressed as mean \pm SEM of 6 rats.

${ }^{* *} \mathrm{P}<0.01,{ }^{* * *} \mathrm{P}<0.001$ vs. $\mathrm{CH}$.

Figure 2. Left ventricular hypertrophy (LVH) index at the end of study (8 weeks) in control SHR (C), untreated hypercholesterolemic SHR $(\mathrm{CH})$, treated hypercholesterolemic SHR with milk casein hydrolyzate (CHL) or milk casein hydrolyzate plus phytosterols (CHLP). Values are expressed as mean \pm SEM of 6 rats.

${ }^{* *} \mathrm{P}<0.01,{ }^{* * *} \mathrm{P}<0.001$ vs. $\mathrm{CH}$.

Figure 3. Liver hypertrophy (LH) index at the end of study (8 weeks) in control SHR (C), untreated hypercholesterolemic SHR $(\mathrm{CH})$, treated hypercholesterolemic SHR with milk casein hydrolyzate (CHL) or milk casein hydrolyzate plus phytosterols (CHLP).

Values are expressed as mean \pm SEM of 6 rats.

${ }^{\# \# \#} \mathrm{P}<0.001$ vs. $\mathrm{C} ;{ }^{*} \mathrm{P}<0.05$ vs. $\mathrm{CH} ;{ }^{+} \mathrm{P}<0.05$ vs. $\mathrm{CHL}$.

Figure 4. Histological sections of liver $(\times 20)$ and hepatic steatosis area $(\%)$ at the end of study (8 weeks) in control SHR (C), untreated hypercholesterolemic SHR (CH), treated hypercholesterolemic SHR with milk casein hydrolyzate $(\mathrm{CHL})$ or milk casein hydrolyzed plus phytosterols (CHLP).

Values are expressed as mean \pm SEM of 6 rats.

${ }^{\# \# \#} \mathrm{P}<0.001$ vs. $\mathrm{C} ;{ }^{* * *} \mathrm{P}<0.001$ vs. $\mathrm{CH} ;{ }^{+++} \mathrm{P}<0.001$ vs. $\mathrm{CHL}$. 
Figure 5. Cumulative concentration-response curves to acetylcholine (a) and sodium nitroprusside (b) in pre-constricted aortic rings from control SHR (C), untreated hypercholesterolemic SHR $(\mathrm{CH})$, treated hypercholesterolemic SHR with milk casein hydrolyzate (CHL) or milk casein hydrolyzed plus phytosterols (CHLP).

Values are expressed as mean \pm SEM of 6 rats.

${ }^{* *} \mathrm{P}<0.01,{ }^{* * *} \mathrm{P}<0.001$ vs. $\mathrm{CH}$.

Figure 6. Cumulative concentration-response curves to phenylephrine in aortic rings from control SHR (C), untreated hypercholesterolemic SHR $(\mathrm{CH})$, treated hypercholesterolemic SHR with milk casein hydrolyzate $(\mathrm{CHL})$ or milk casein hydrolyzed plus phytosterols (CHLP).

Values are expressed as mean \pm SEM of 6 rats.

${ }^{*} \mathrm{P}<0.05,{ }^{* *} \mathrm{P}<0.01$ vs. $\mathrm{CH}$.

Figure 7. Vascular superoxide anion $\left(\mathrm{O}_{2}{ }^{-}\right)$generation stimulated by NADPH addition in aortic rings from control SHR $(\mathrm{C})$, untreated hypercholesterolemic SHR $(\mathrm{CH})$, treated hypercholesterolemic SHR with milk casein hydrolyzate $(\mathrm{CHL})$ or milk casein hydrolyzed plus phytosterols (CHLP).

Values are expressed as mean \pm SEM of 6 rats.

${ }^{\# \#} \mathrm{P}<0.001$ vs. $\mathrm{C} ;{ }^{*} \mathrm{P}<0.05$, ${ }^{* *} \mathrm{P}<0.001$ vs. $\mathrm{CH}$. 


\section{Table 1.}

Table 1. Daily intake of feed, water consumption, weight gain, lipid profile, atherogenic index $(\mathrm{Al})$, transaminases (AST, $A L T)$ and lipid peroxidation (TBARS) at the end of experiment (8 weeks) in control SHR (C), untreated hypercholesterolemic SHR $(\mathrm{CH})$, treated hypercholesterolemic SHR with milk casein hydrolyzate (CHL) or milk casein hydrolyzate plus phytosterols (CHLP).

\begin{tabular}{lcccc}
\hline & C & CH & CHL & CHLP \\
\hline Feed intake (g/day) & $23.1 \pm 0.2$ & $22.8 \pm 0.3$ & $22.7 \pm 0.2$ & $23.3 \pm 0.2$ \\
Water consumption (mL/day) & $35.4 \pm 1.2$ & $36.2 \pm 0.9$ & $37.1 \pm 1.1$ & $36.7 \pm 0.8$ \\
Weight gain (g/8 weeks) & $93.8 \pm 8.4$ & $89.0 \pm 4.6$ & $102.8 \pm 5.3$ & $109.4 \pm 4.3$ \\
TC (mg/dL) & $84.5 \pm 6.8$ & $145.3 \pm 7.6^{\# \#}$ & $147.7 \pm 10.4$ & $94.5 \pm 7.0^{* *,+++}$ \\
TG (mg/dL) & $97.0 \pm 19.3$ & $118.7 \pm 16.3$ & $81.2 \pm 9.6$ & $98.7 \pm 7.0$ \\
LDLc (mg/dL) & $36.5 \pm 5.2$ & $93.8 \pm 9.0^{\# \#}$ & $103.1 \pm 9.8$ & $42.6 \pm 7.4^{* *,+++}$ \\
HDLc (mg/dL) & $38.0 \pm 3.7$ & $27.8 \pm 1.2^{\#}$ & $28.3 \pm 2.8$ & $32.1 \pm 1.5$ \\
Al & $1.3 \pm 0.3$ & $4.3 \pm 0.4^{\# \#}$ & $4.5 \pm 0.7$ & $2.0 \pm 0.2^{* *,++}$ \\
AST (IU/L) & $42.2 \pm 4.3$ & $103.8 \pm 15.6^{\# \#}$ & $86.2 \pm 14.7$ & $48.6 \pm 2.5^{*}$ \\
ALT (IU/L) & $24.8 \pm 1.6$ & $69.6 \pm 4.0^{\# \#}$ & $31.4 \pm 2.7^{* * *}$ & $27.4 \pm 3.8^{* * *}$ \\
TBARS ( $\mu$ M) & $2.8 \pm 0.1$ & $4.3 \pm 0.4^{\# \#}$ & $3.8 \pm 0.2$ & $3.2 \pm 0.2^{*}$ \\
\hline
\end{tabular}

TC, total Cholesterol; TG, Triacylglycerols; LDLC, low density lipoproteincholesterol; HDLc, high density lipoprotein-cholesterol; AST, aspartate transaminase; ALT, alanine transaminase.

Values are expressed as mean \pm SEM of 6 rats.

${ }^{\#} \mathrm{P}<0.05,{ }^{\# \#} \mathrm{P}<0.001$ vs. $\mathrm{C} ;{ }^{*} \mathrm{P}<0.05,{ }^{* *} \mathrm{P}<0.01$ vs. $\mathrm{CH} ;{ }^{++} \mathrm{P}<0.01,{ }^{+++} \mathrm{P}<0.001$ vs. $\mathrm{CHL}$. 


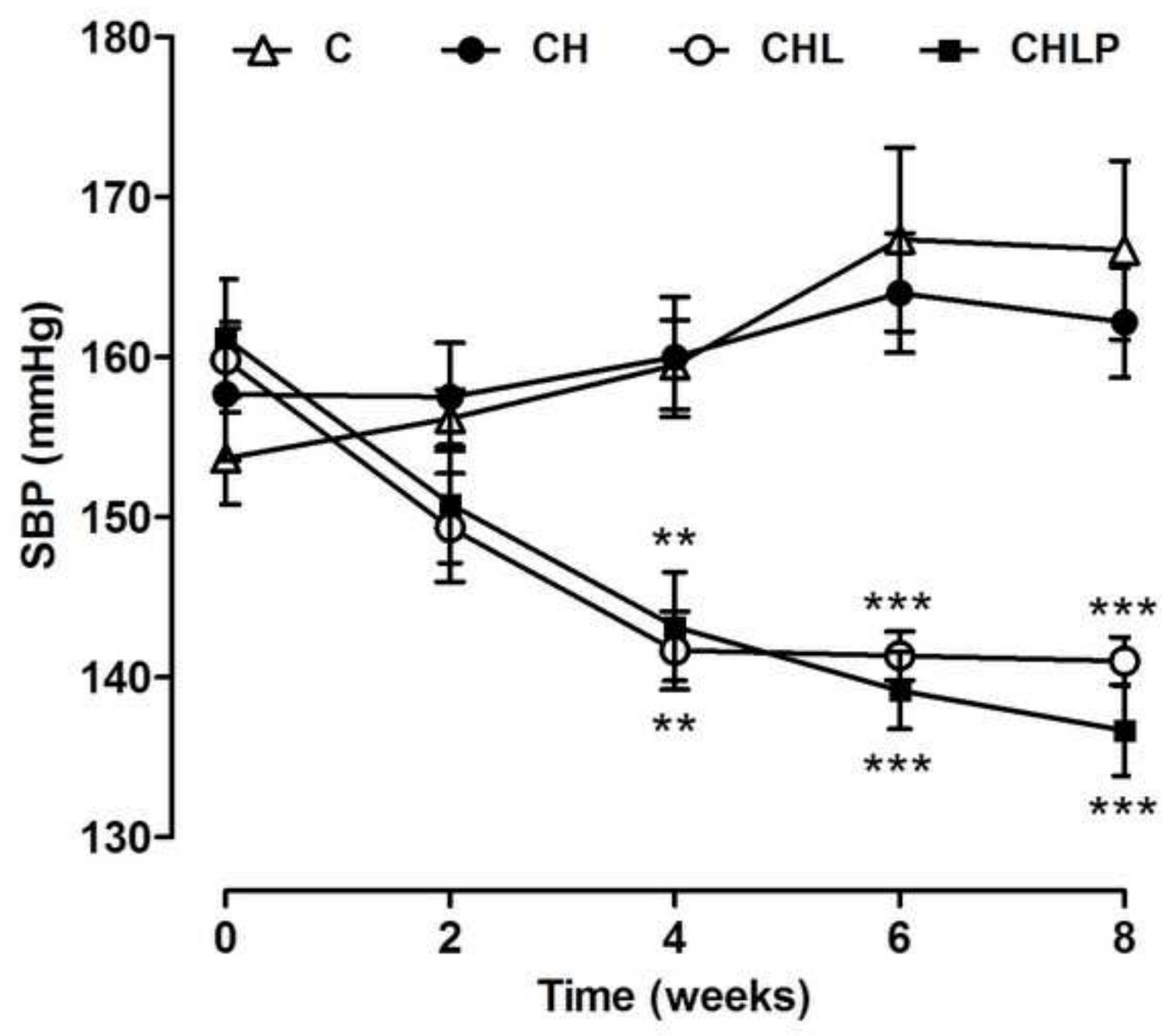




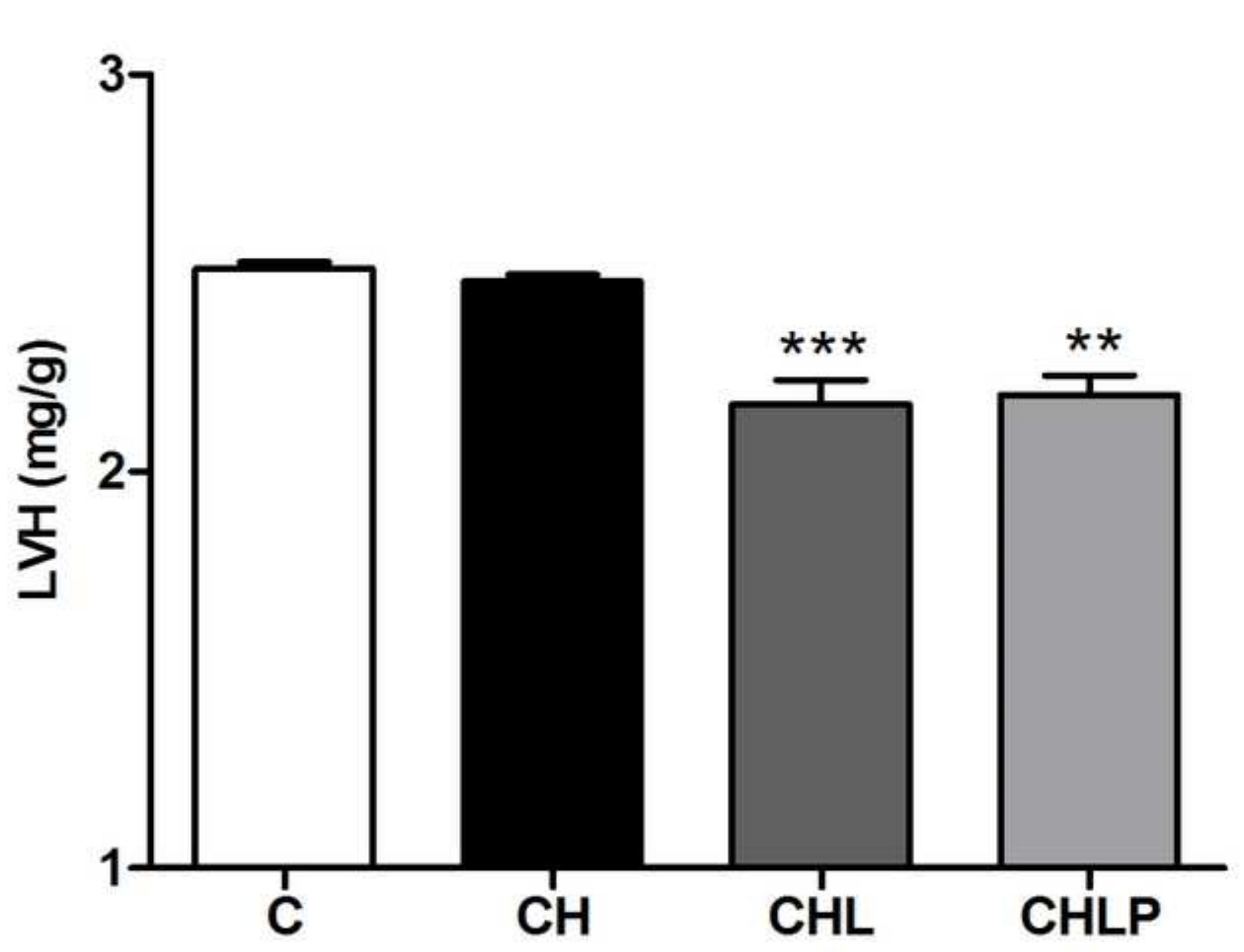

\section{Click here to download high resolution image}


Click here to download high resolution image
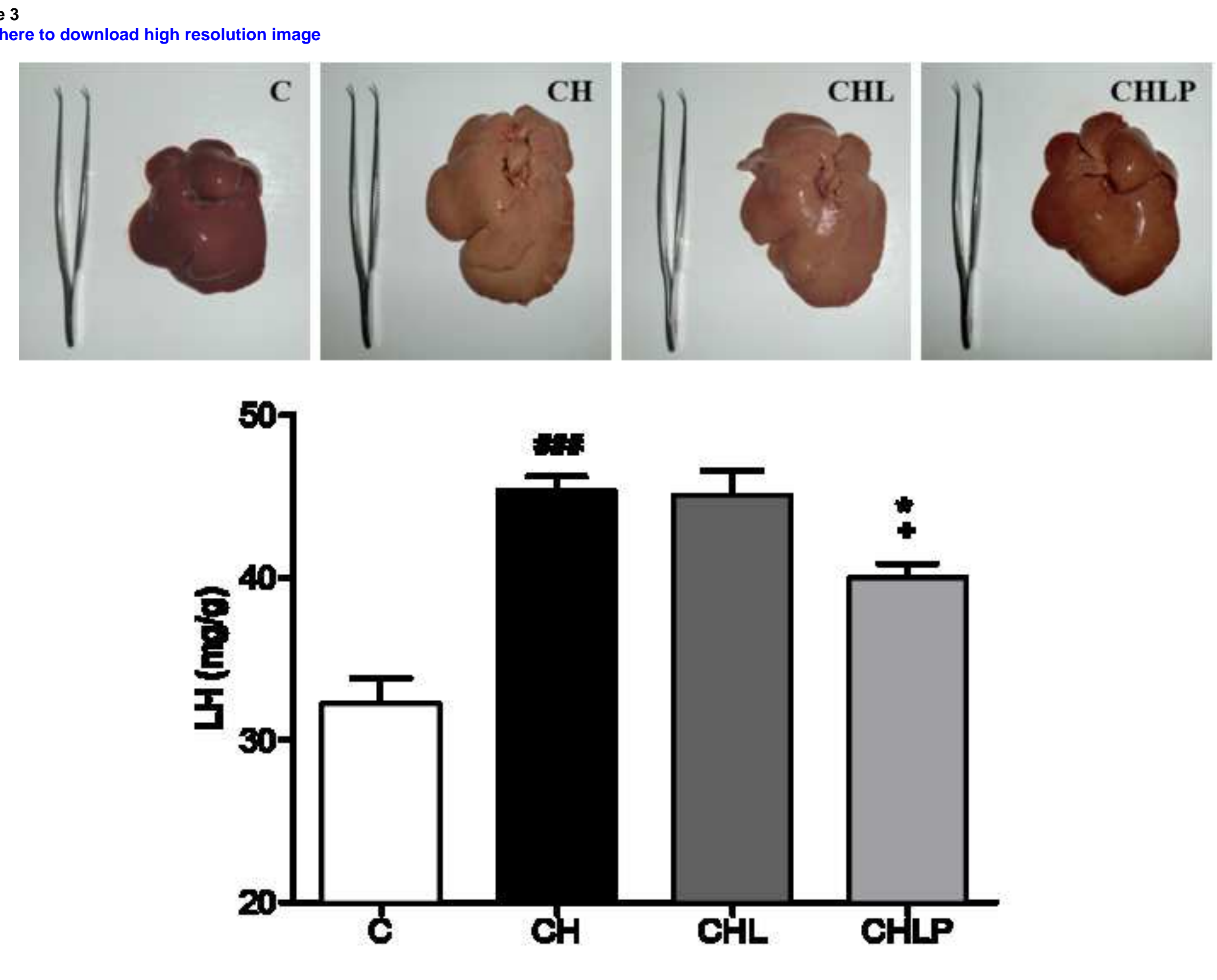

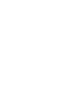


Click here to download high resolution image
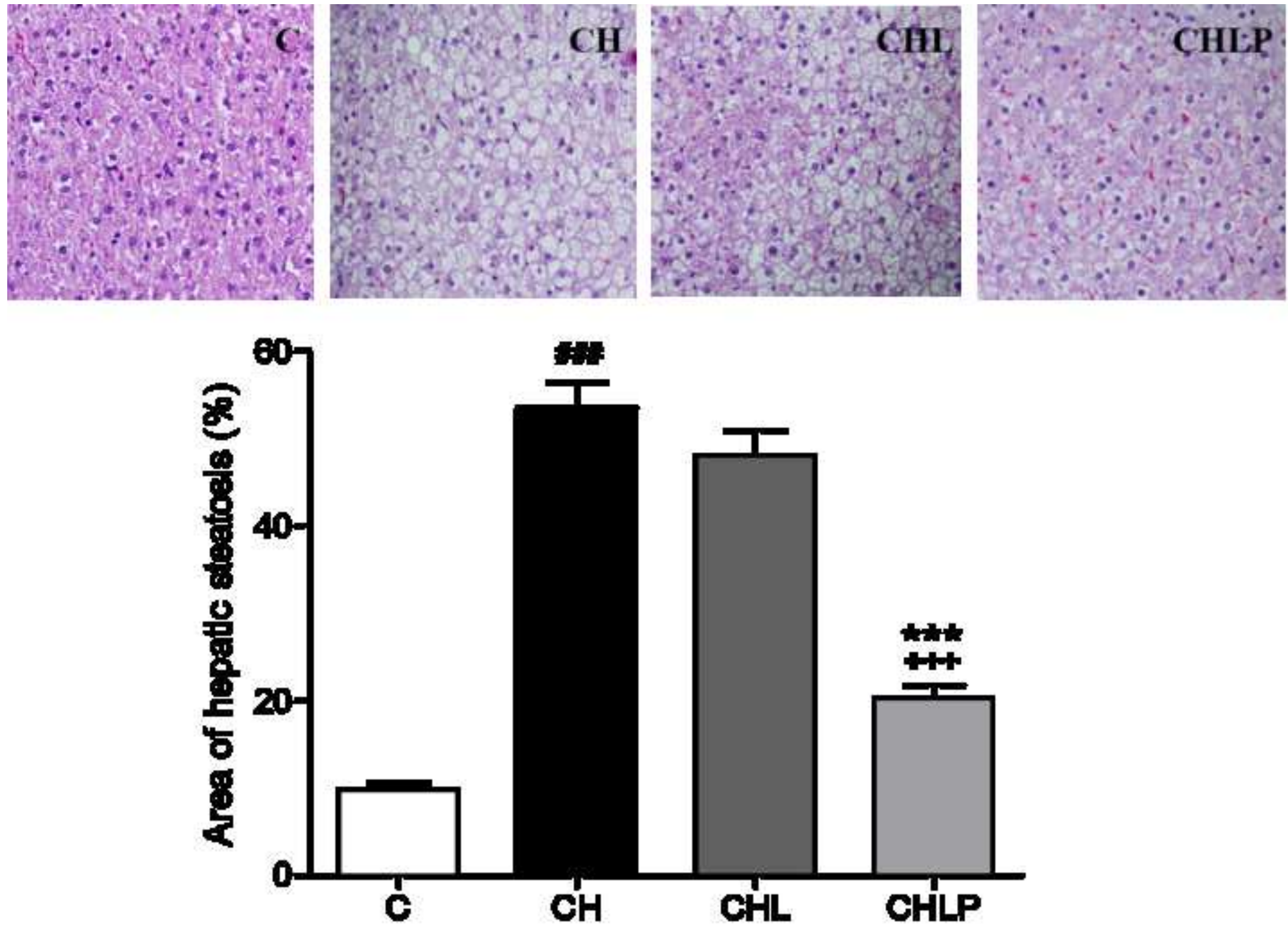
Figure 5

Click here to download high resolution image
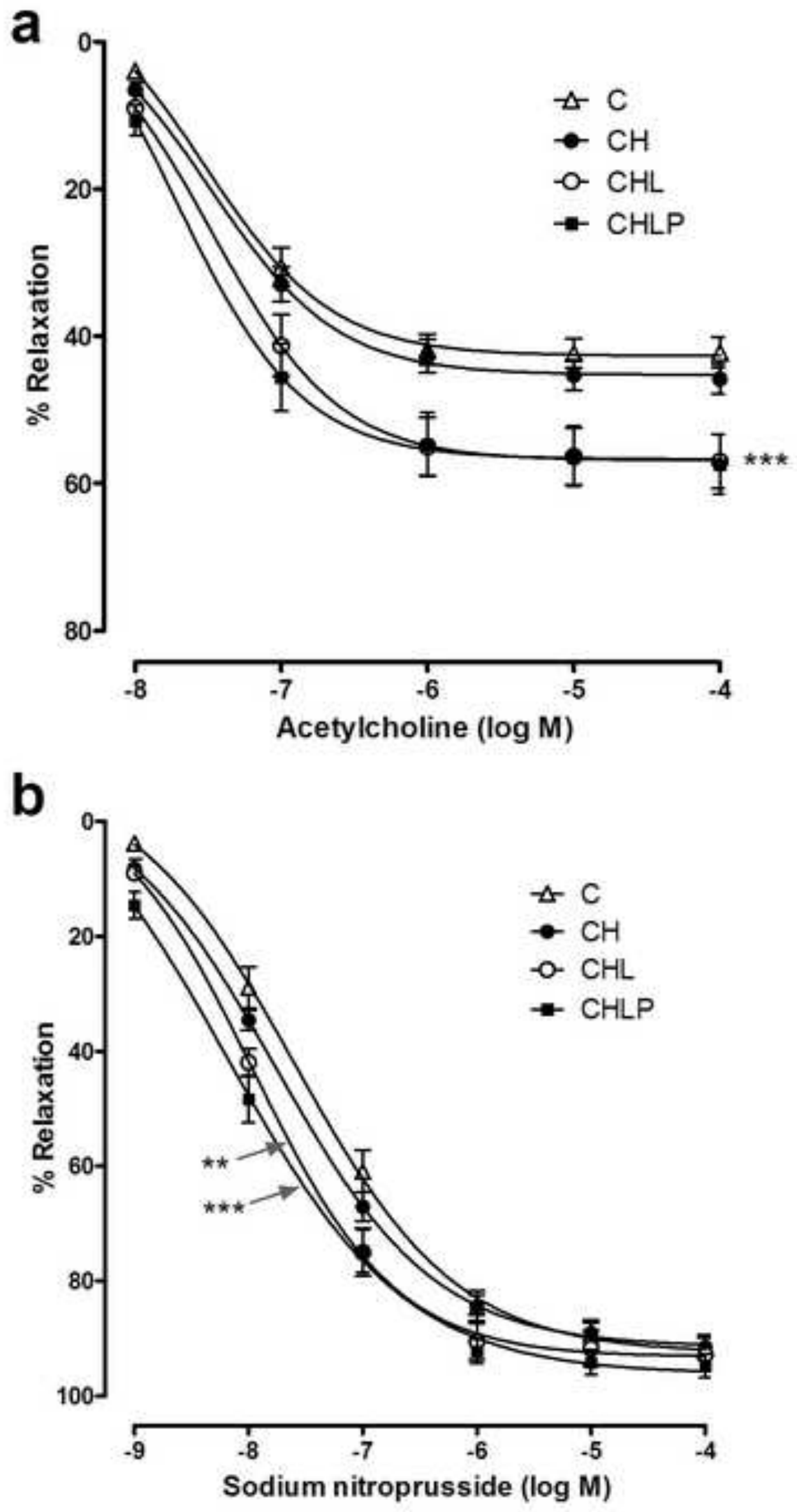


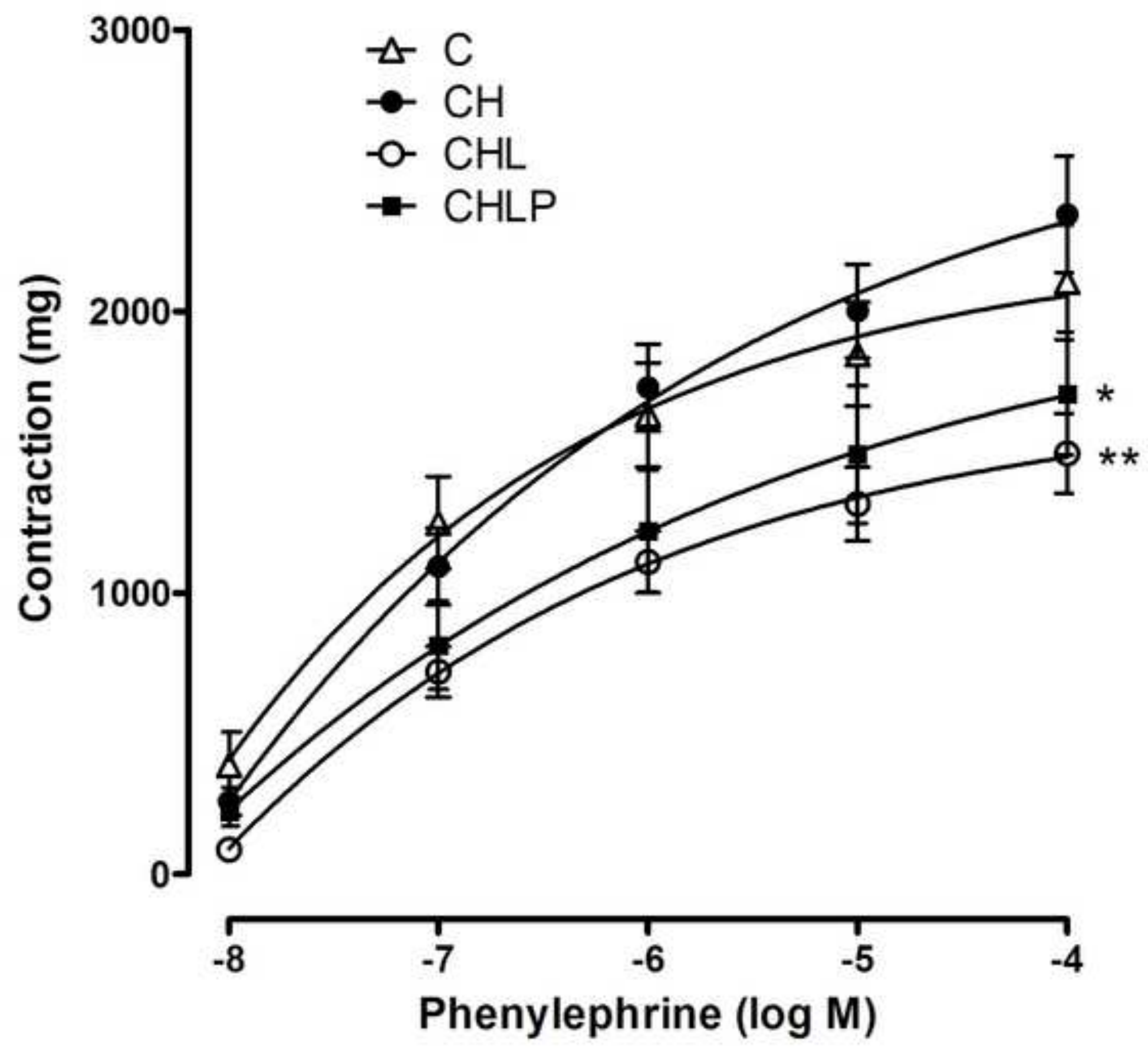




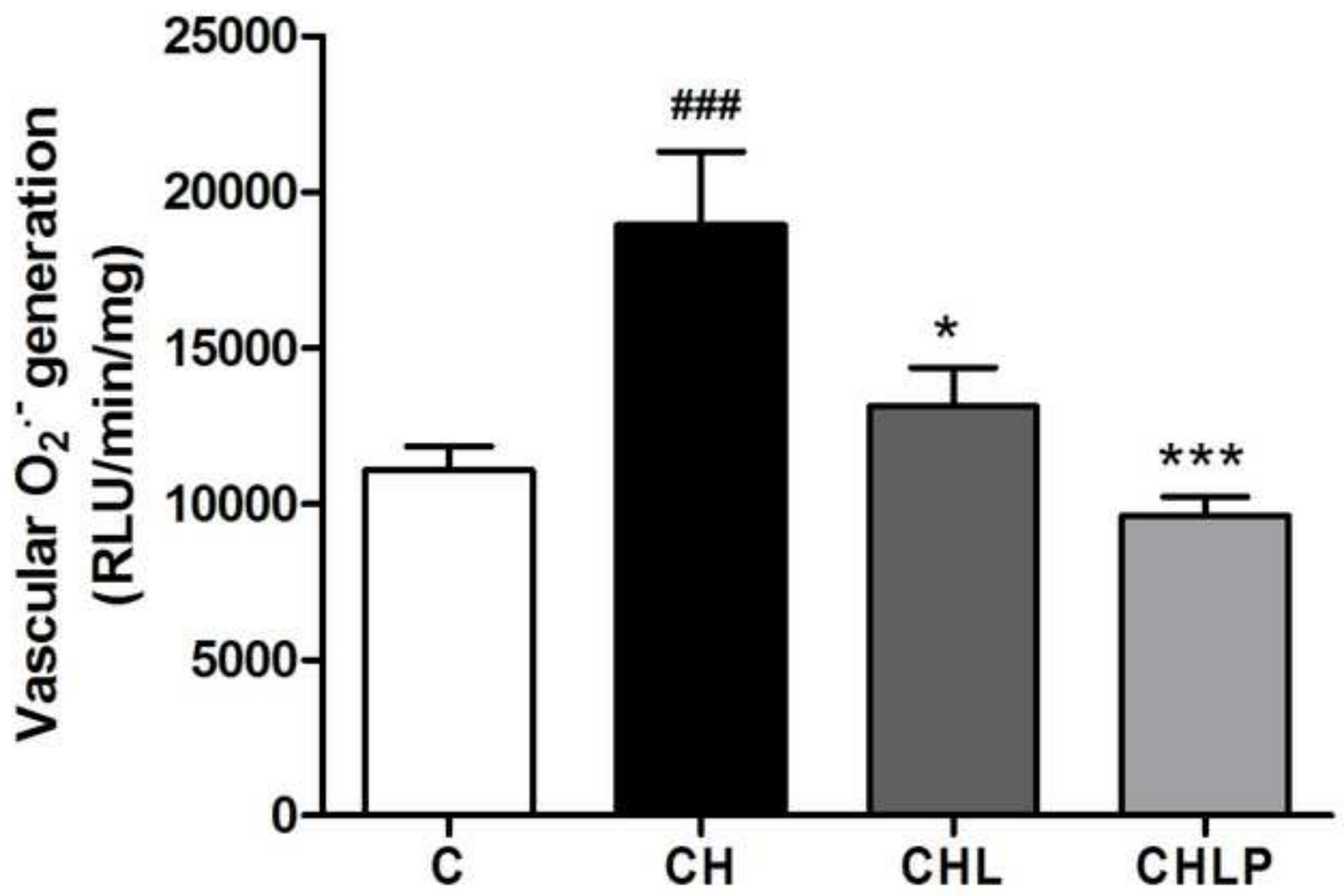

